\title{
An efficient and blistering reduction of 4-nitrophenol by green synthesized silver nanoparticles
}

\author{
Jasneet Kaur ${ }^{1}$. Jagpreet Singh ${ }^{1} \cdot$ Mohit Rawat $^{1}$
}

(C) Springer Nature Switzerland AG 2019

\begin{abstract}
The present work describes a clean, green and cost efficient approach for the synthesis of biogenic silver nanoparticles from the Psidium guajava leaf extract. The UV-Visible spectrum shows a sharp peak at $413 \mathrm{~nm}$ revealing the formation of silver nanoparticles (Ag NPs). The optical and morphological characterization confirms the formation of stable and mono disperse biogenic silver nanoparticles having average diameter in range of 20-30 nm. FTIR study confirms that the strong capping and reduction potential Psidium guajava leaf extract for the synthesis of Ag NPs. The synthesized Ag NPs shows the prodigious potential for the reduction of 4-nitrophenol (4-NP) to 4-aminophenol (4-AP) within 8 min (ultra-high speed) with rate constant $0.159 \mathrm{~min}^{-1}$. Kinetic study elucidate that the catalytic reduction follows the pseudo first order with $R^{2}$ value of 0.975 .
\end{abstract}

Keywords Silver NPs · Psidium guajava · Catalysis · 4-Nitrophenol · Green synthesis

\section{Introduction}

In the modern era, the water is getting depleted by number of pollutants present in the waste effluents from the industries. It is necessary to remove these pollutants from the waste water on the account of their toxicity. The nitro group containing pollutants are of major concern as they are difficult to reduce because of their toxic behaviour [1-3]. Compounds like 4-nitro phenol (4-NP) are not only toxic but also anthropogenic and inhibitory in nature so their reduction is an issue of major importance. 4-nitrophenol is a phenolic compound, constitute one nitro group present on the benzene ring diagonally to the hydroxyl group. 4-NP cause eyes irritation and inflammation. It interacts with blood and forms methaemoglobin which results in forming methemoglobinemia; that causes cyanosis, confusion and unconsciousness. When ingested, it causes abdominal pain and vomiting. Moreover, 4-NP and its by-products are used for the further synthesis of herbicides, insecticides and pesticides that causes threat to environment as well as to human beings $[4,5]$.

In the recent decades, with the increasing scope of nanotechnology the borohydride reduction of these nitro group compounds (4-nitrophenol) into useful and harmless compound (4-Aminophenol) by metal nanoparticles has been seeking attention due to the easy availability of the reaction conditions [6, 7]. Metal nanoparticles (NPs) because of their unique properties like large surface area to volume ratio, large surface energies as compared to their bulk counterparts; has numerous applications in biological, electrochemical and medical fields [8-10]. There are various metal nanoparticles were used for the reduction of these nitro derivatives. Among all the metal NPs, silver (Ag) NPs are of substantial interest as of its ability to tune plasmon resonance at any wavelength in visible spectrum region and it acts as good catalyst under normal conditions and ambient temperatures. Ag NPs have numerous applications like in catalysis [11], anti-microbial and in medicinal field [12]. There is number of methodologies

Mohit Rawat, mohitnano.nit@gmail.com | 'Department of Nanotechnology, Sri Guru Granth Sahib World University, Fatehgarh Sahib, Punjab 140406, India.

SN Applied Sciences (2019) 1:1060 | https://doi.org/10.1007/s42452-019-1088-x 
to synthesize silver nanoparticles, such as thermal decomposition [13], microwave assisted [14], electrochemical [15] and green chemistry [8]. Due to the use of many chemicals in synthesis processes, the manufacturing process would be costly and it would cause toxicity. Therefore, an ecofriendly and cheapest method is gaining importance now a day. Biosynthetic methodology, using plant extract or microorganisms is usually more preferred over the chemical synthetic procedures and physical methods. Microorganisms such as bacteria, yeast or fungi can be used in synthesizing metal nanoparticles. Plant extract's constituent acts as reducing agents and stabilizing agents to form the metal NPs. Some of the plants like Pelargonium graveolens [16], Azadirachta indica [17], Lemongrass [18], Cinnamomum Camphora [19], Emblica officinalis [20], Carica papaya [21-27], Oscium sanctum [7] have the ability to reduce $\mathrm{AgNO}_{3}$ to silver NPs.

In the present work, we adopted the one step, cost effective and eco-friendly method to synthesize the silver nanoparticles from the Psidium guajava (guava) leave extract. The synthesized silver nanoparticles were employed for the catalytic reduction of 4-NP into 4-AP. Also, the 4- AP has many useful pharmaceutical applications such as synthesis of paracetamol. Thus, this approach demonstrates the non-toxic, one pot innovative and green approach for the synthesis of NPs and their further use in the environment.

\section{Materials and methodology}

\subsection{Materials}

The Psidium guajava leaves are collected from the nearby garden in Fatehgarh Sahib. Silver nitrate salt was purchased from Sigma Aldrich. The other chemicals 4-NP and Sodium Borohydride $\left(\mathrm{NaBH}_{4}\right)$ were purchased from Merck, Germany for the further process. All these chemicals are of analytical grade and used without any purification. Double distilled water is used for aqueous solution. Whatman no. 1 filter paper is used for filtration.

\subsection{Preparation of extract}

The collected Psidium guajava leaves were washed with DI water and sun dried to eliminate water. Then the leaves were cut down into small fine piece. The $4 \mathrm{~g}$ leaves were weighed and boiled in $100 \mathrm{ml} \mathrm{DI}$ water. After $1 \mathrm{~h}$ lightish green yellow solution formed and separated from the particulate matter by using Whatman filter paper No: 1 . The obtained solution was stored at $4{ }^{\circ} \mathrm{C}$.

\subsection{Synthesis of silver nanoparticles}

Firstly, solution of $\mathrm{AgNO}_{3}$ is prepared by adding $0.016 \mathrm{~g}$ of $10^{-2} \mathrm{M} \mathrm{AgNO}_{3}$ in $100 \mathrm{ml}$ of DI water. After that the $1 \mathrm{ml}$ of the prepared extract solution was added drop wise to the $50 \mathrm{ml}$ of $\mathrm{AgNO}_{3}$ solution with continuous mild stirring. After sometime the colour of the solution starts to change from lightish green yellow to reddish brown indicating the formation of silver nanoparticles (Ag NPs).

\subsection{Catalytic activity}

To check the catalytic activity of synthesized Ag NPs, the reduction of 4-nitrophenol was carried out in the quartz cuvette in the presence of the sodium borohydride solution. In the cuvette $2.7 \mathrm{ml} \mathrm{DI}$ water taken. Then, the $30 \mu \mathrm{l}$ of $\left(10^{-2} \mathrm{M}\right) 4$-nitrophenol was mixed with water, and subsequently $200 \mu \mathrm{l}$ of $\left(10^{-1} \mathrm{M}\right) \mathrm{NaBH}_{4}$ was added. Once all the solutions get mixed, then $10 \mu \mathrm{l}$ of Ag NPs (catalyst) were added. Afterwards, The catalytic reaction was monitored by UV-Visible spectrophotometer with different time intervals. With the passage of time, yellow color solution turned into colorless solution indicating the reduction of 4-NP into 4-AP.

\section{Results and discussion}

\subsection{UV-visible analysis}

$1 \mathrm{ml}$ of prepared extract was added in the $\mathrm{AgNO}_{3}$ solution for the reduction of $\mathrm{Ag}^{+}$into $\mathrm{Ag}^{0}$. The reaction was monitored spectrophotometerically on UV-vis spectrometer (model no. UV-2600, SHIMADZU, Japan). The change of color from the light greenish yellow into reddish brown color was observed, due to the surface plasmon excitations in the metal atoms. The formation of Ag NPs was confirmed by surface plasmon resonance phenomenon. The $\lambda_{\max }$ values for the biosynthesized $\mathrm{Ag}$ NPs were reported in between 400 and $500 \mathrm{~nm}$ that is a visible range. Figure 1 shows the Ag NPs synthesized by $1 \mathrm{ml}$ extract volume. The particles synthesized by $1 \mathrm{ml}$ extract gives sharp and strong absorption band at $\lambda_{\max }$ $413 \mathrm{~nm}$.

\subsection{Zetasizer analysis}

The average diameter and particle size distribution (PSD) is determined by particle size analyzer (MalvernZEN-1690) that is based on laser diffraction technique. The average diameter of the biosynthesized Ag NPs was 


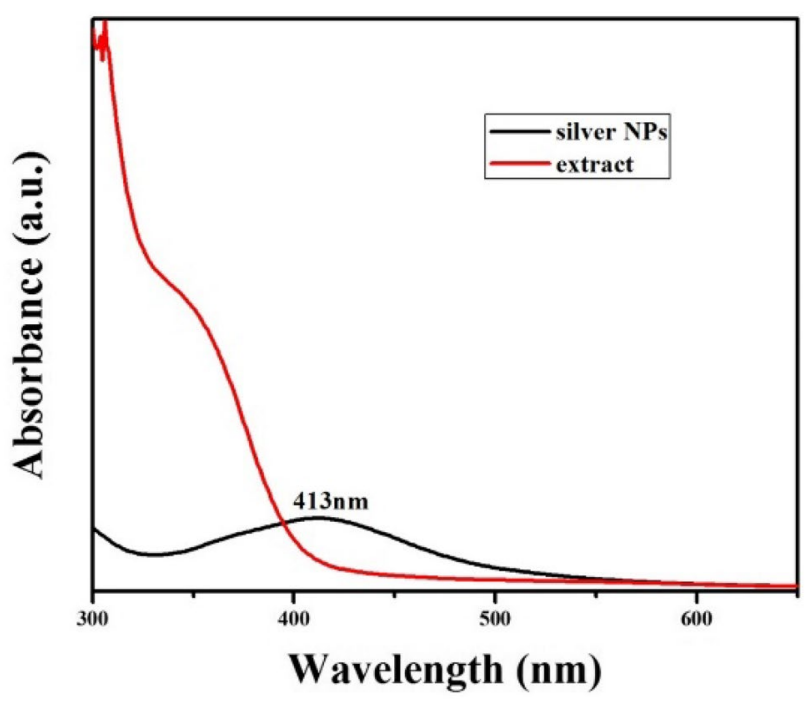

Fig. 1 UV-visible spectrum of Ag NPs (black line) and Psidium guajava leaf extract (red line). The sharp band at $413 \mathrm{~nm}$ indicates the formation of Ag NPs

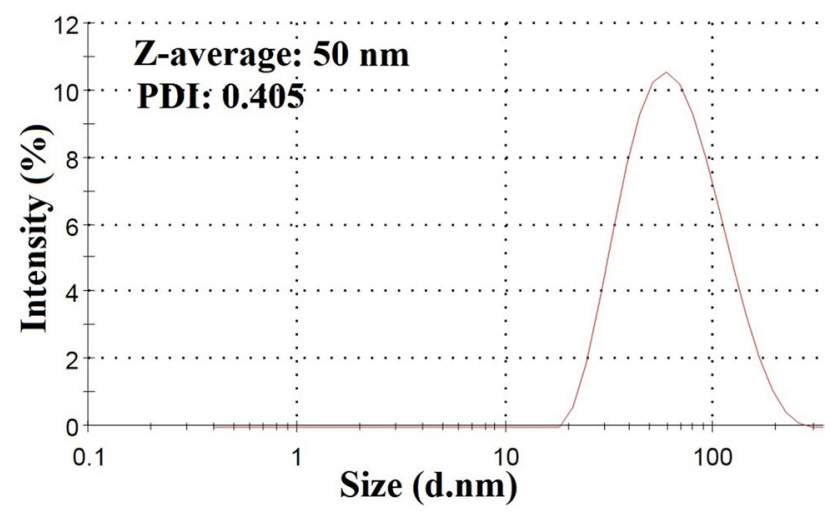

Fig. 2 DLS graph shows the particle size distribution of Ag NPs

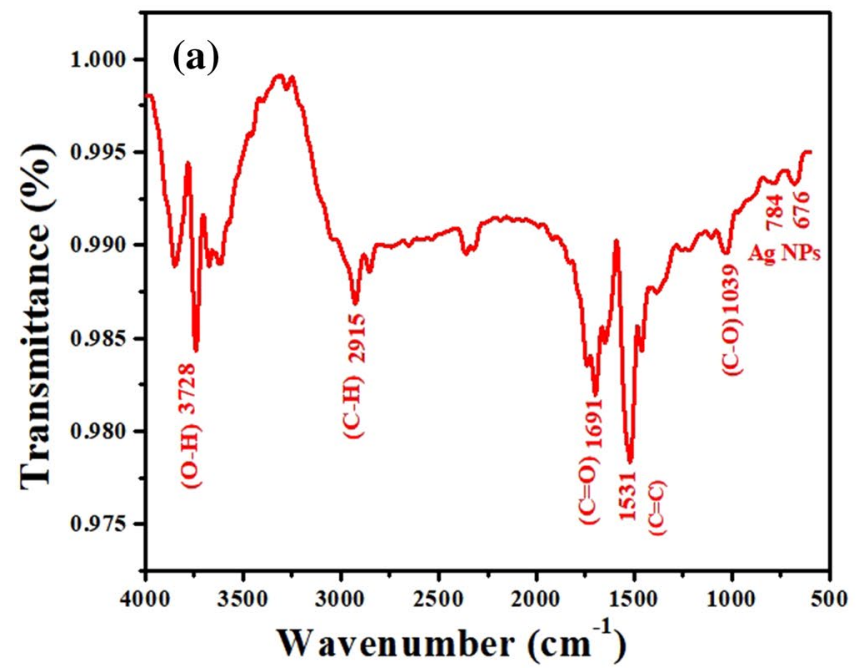

estimated to be 50.90 with corresponding PDI value of 0.405 as depicted in Fig. 2.

\subsection{FTIR analysis}

The FTIR spectra of the Ag NPs exhibit the strong bands at $3728 \mathrm{~cm}^{-1}(\mathrm{O}-\mathrm{H}), 2915 \mathrm{~cm}^{-1}(\mathrm{C}-\mathrm{H}), 1691 \mathrm{~cm}^{-1}(\mathrm{C}=\mathrm{O})$, $1531 \mathrm{~cm}^{-1}(\mathrm{C}=\mathrm{C}), 1039 \mathrm{~cm}^{-1}(\mathrm{C}-\mathrm{O})$ and 784 and $676 \mathrm{~cm}^{-1}$ as shown in Fig. 3a. These functional groups (phenols, flavonoids, proteins) originated from Psidium guajava extract which can be observed in Fig. 3b. Thus, by comparing Fig. 3a, b, it was suggested that the these phytochemicals (present in extract) were responsible for the reduction and capping of Ag NPs [22-25]. Additionally, the capping capability of phytochemicals were also observed in HRTEM micrographs (Fig. 5). The formation of the silver nanoparticles confirmed by the characteristics peak at 676 and $784 \mathrm{~cm}^{-1}$ due to the formation of bond between $\mathrm{Ag}$ and the $\mathrm{O}$-atoms of the phytochemicals. All these values were in agreement with the already reported study $[26,27]$.

\subsection{XRD analysis}

The crystal structure and phase purity of synthesized Ag NPs was investigated by XRD study performed on X-ray diffractometer (model no. DY 3190, PANalytical XPERT-PRO, Japan). The XRD spectra showed the diffraction peaks at $37.9^{\circ}, 44.1^{\circ}, 64.4^{\circ}, 77.5^{\circ}$ corresponding diffraction planes (111), (200), (220) and (311) respectively. Therefore, the XRD analysis confirms the cubic crystal structure of $\mathrm{Ag}$ nanoparticles according to JCPDS Card No. 04-0783 (Fig. 4).

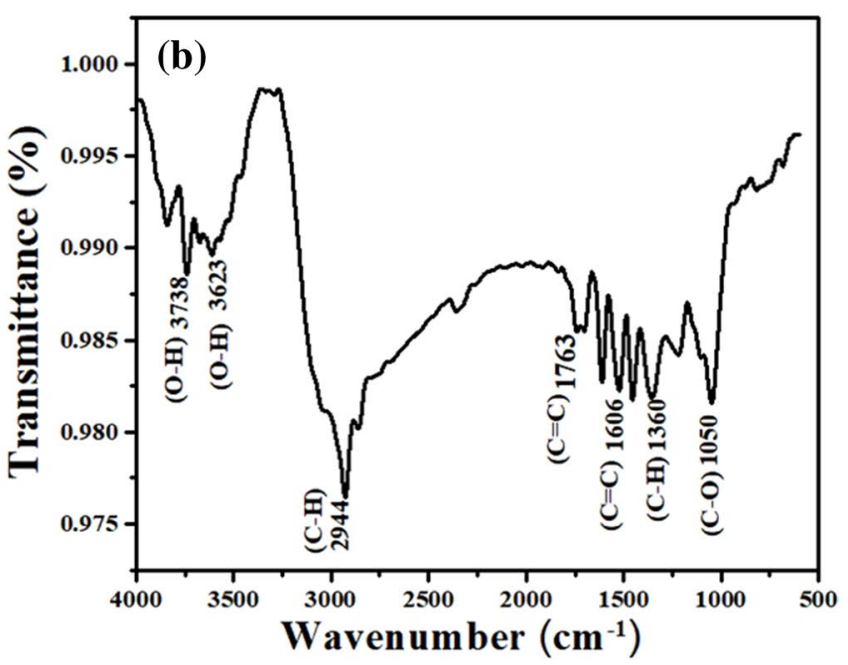

Fig. 3 FTIR spectra of a synthesized Ag NPs and $\mathbf{b}$ Psidium guajava extract 


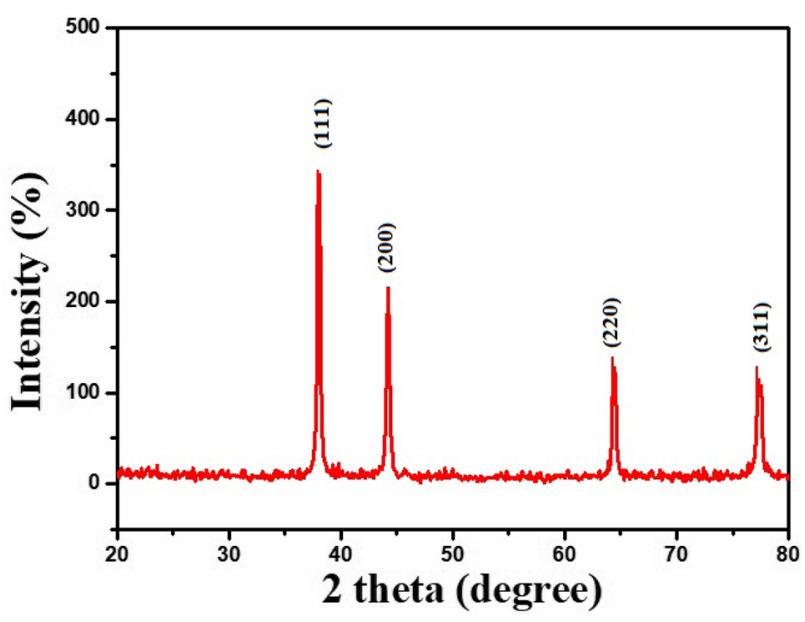

Fig. 4 XRD spectra of synthesized Ag NPs

\subsection{HR-tem}

The structural and elemental analysis of Ag NPs was employed by high resolution transmission electron microscopy (HR-TEM) and presented in Fig. 5. The observed average diameter from the HR-TEM analysis was in range of 20-30 nm with narrow particle size distribution. Also, the strong capping potential of phytochemicals present in Psidium guajava extract can be easily observed (small circles around the particles) in HR-TEM micrographs.

\subsection{Catalytic reduction studies}

The catalytic activity of synthesized silver nanoparticles was checked by reducing 4-NP in the presence of sodium borohydride. 4-nitrophenol is highly toxic and due to the presence of electron withdrawing nitro group so it is difficult to remove this by simple oxidation and hydrolysis methods. The kinetics of the reduction process was studied spectrophotometrically as shown in the Fig. 6a. At $\mathrm{t}=0 \mathrm{~min}$, the UV spectra as characterized by sharp absorption band at $400 \mathrm{~nm}$ indicating the formation of the nitrophenolate ion. Addition of biosynthesized Ag NPs will result in the rapid decline of the absorption intensity at $400 \mathrm{~nm}$ which is accompanied by the formation of wider band at $298 \mathrm{~nm}$ owing to the formation of 4-aminophenol. The color of the solution turns from bright yellow to colourless within $8 \mathrm{~min}$, which signifies the efficient catalytic potential of synthesized Ag NPs and the importance of this study as well. The kinetic study confirms the catalytic reduction follows pseudo first order with rate constant $0.1579 \mathrm{~min}^{-1}$ as shown in Fig. 6b. Moreover, the reduction of 4-NP without Ag NPs is not possible, due to high activation energy barrier $[28,29]$. Additionally, to validate the efficacy of present study, a comparison of previous studies was investigated as described in Table 1. It was observed that many studies used complex, expensive and harmful process to synthesize silver nanoparticles and their composites for reduction of 4-NP. Also, they require more time for completer reduction of 4-NP then the present study. Thus, this study provides many advantages such as adaptability of eco-friendly, inexpensive and simple process for the synthesis of Ag NPs, which have remarkable potential for the complete reduction of 4-NP with ultra-high speed (8 $\mathrm{min}$ ).

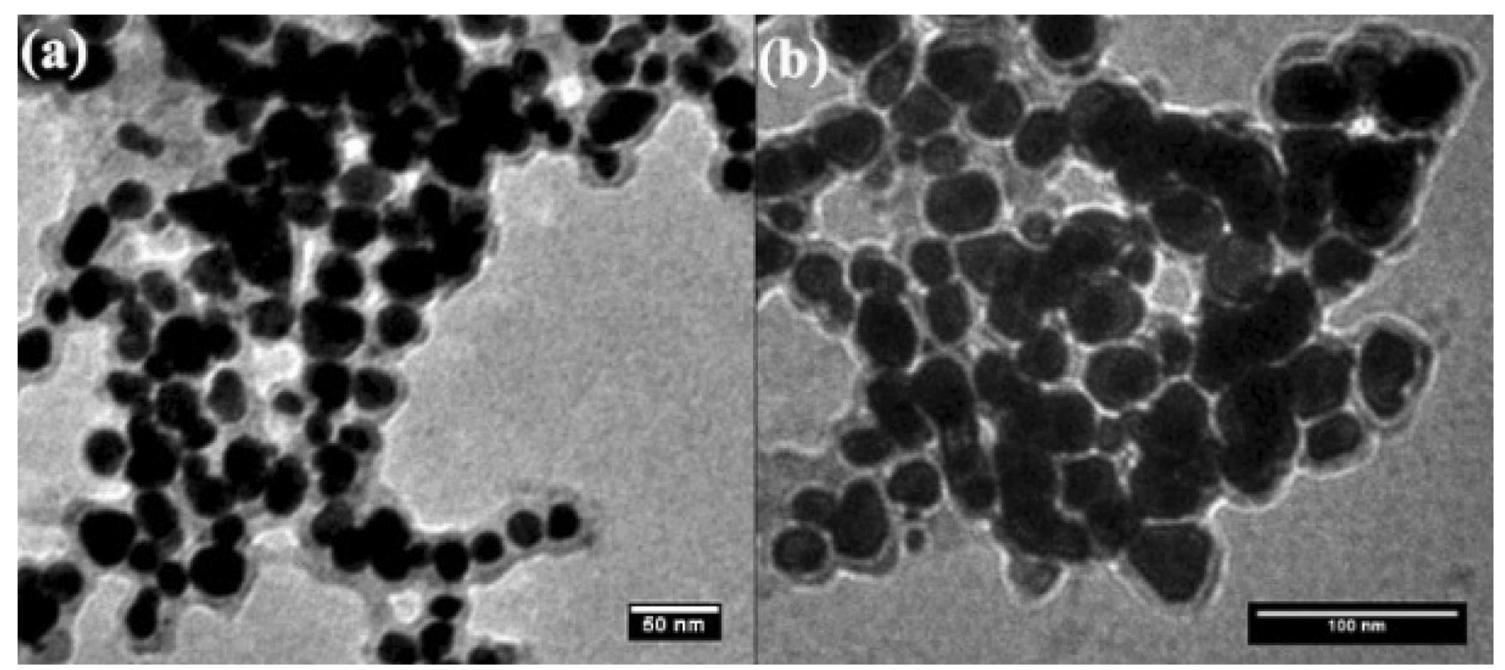

Fig. 5 TEM images Ag NP's at a $50 \mathrm{~nm}$ and b $100 \mathrm{~nm}$ scale bar

SN Applied Sciences

A SPRINGER NATURE journal 

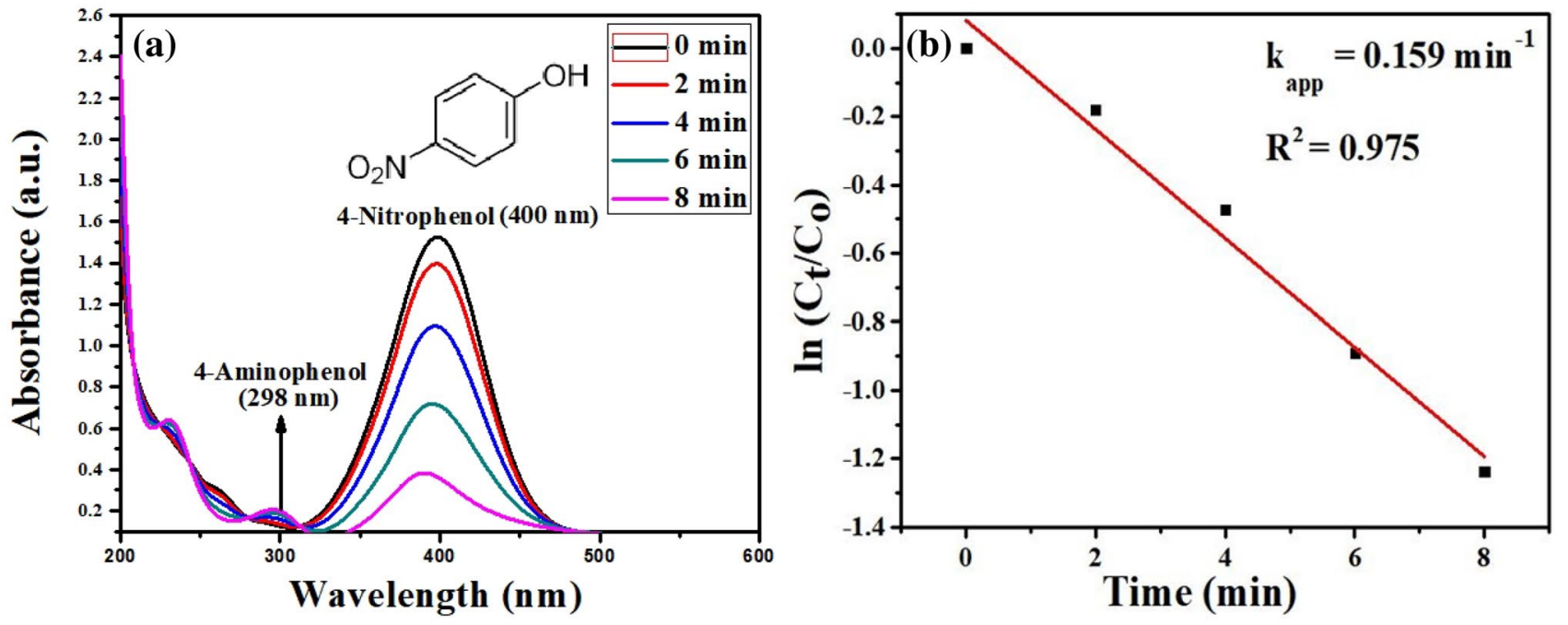

Fig. 6 Schematic shows the a UV-Visible spectrum showing catalytic reduction of 4-Nitrophenol (400 nm) to 4-Aminophenol (298 $\mathrm{nm}$ ) by $10 \mu \mathrm{l}$ of $\mathrm{Ag} \mathrm{NPs}$ in the presence of $\mathrm{NaBH}_{4}$ at room temperature (Inset: chemical structure of 4-NP) and $\mathbf{b}$ kinetic study of catalytic reduction

Table 1 Performance comparison of Ag NPs based catalysts for the reduction of 4-nitrophenol to 4-aminophenol

\begin{tabular}{lllll}
\hline Catalyst & Synthesis method & Catalyst loading & Reaction time & References \\
\hline Ag NPs & Biodegradable amphiphilic copolymers & $30 \mu \mathrm{L}$ & $12 \mathrm{~min}$ & {$[28]$} \\
Ag-P(NIPAM-co-AAm) & Precipitation polymerization & $37.18 \mathrm{mg}$ & $25 \mathrm{~min}$ & {$[30]$} \\
Au, Ag NPs & Photochemical green & $20 \mathrm{mg}$ & $45 \mathrm{~min}$ & $60 \mathrm{~min}$ \\
Ag NPs by kollicoat & Chemical & $50 \mathrm{mg}$ & $8 \mathrm{~min}$ & {$[32]$} \\
Biogenic Ag NPs & Green & $10 \mu \mathrm{L}$ & Present study \\
\hline
\end{tabular}

\section{Conclusions}

In conclusion, present study demonstrates a innovative and effective, one step method for the synthesis of the silver nanoparticles using the Psidium guajava leaves, that provides a greener route for the synthesis process. Spectroscopic and electronic microscopic studies confirmed the optimized synthesis of stable biogenic silver nanoparticles with uniform size distribution and average size about 20-30 nm. The synthesized Ag NPs exhibit the excellent catalytic activity by the complete reduction of 4-NP into 4-aminophenol with ultrahigh speed. Thus, this study explores a simple, greener and cost effectively approach for the synthesis of biogenic silver NPs and applicability of these NPs for the removal of toxic pollutants from the water resources.

Acknowledgements This work was supported by financial assistance received from Shromani Gurdwara Prabhandak Committee (SGPC), Amritsar. Authors are thankful to Vice-Chancellor, SGGSW University for providing necessary laboratory facilities.

\section{Compliance with ethical standards}

Conflict of interest The authors declare that they have no conflict of interest.

\section{References}

1. Corma A, Serna P (2006) Chemoselective hydrogenation of nitro compounds with supported gold catalysts. Science 313:332334. https://doi.org/10.1126/science.1128383

2. Ju K-S, Parales RE (2010) Nitroaromatic compounds, from synthesis to biodegradation. Microbiol Mol Biol Rev 74:250-272. https://doi.org/10.1128/MMBR.00006-10

3. Kovacic P, Somanathan R (2014) Nitroaromatic compounds: environmental toxicity, carcinogenicity, mutagenicity, therapy and mechanism. J Appl Toxicol 34:810-824. https://doi. org/10.1002/jat.2980

4. Chiou JR, Lai BH, Hsu KC, Chen DH (2013) One-pot green synthesis of silver/iron oxide composite nanoparticles for 4-nitrophenol reduction. J Hazard Mater 248-249:394-400. https://doi. org/10.1016/j.jhazmat.2013.01.030 
5. Zhao B, Mele G, Pio I et al (2010) Degradation of 4-nitrophenol (4-NP) using $\mathrm{Fe}-\mathrm{TiO} 2$ as a heterogeneous photo-Fenton catalyst. J Hazard Mater 176:569-574. https://doi.org/10.1016/j.jhazm at.2009.11.066

6. Singh J, Kukkar P, Sammi H, et al (2017) Enhanced catalytic reduction of 4-nitrophenol and congo red dye by silver nanoparticles prepared from Azadirachta indica leaf extract under direct sunlight exposure. Part Sci Technol 0:1-10. https://doi. org/10.1080/02726351.2017.1390512

7. Singh J, Mehta A, Rawat M, Basu S (2018) Green synthesis of silver nanoparticles using sun dried tulsi leaves and its catalytic application for 4-Nitrophenol reduction. J Environ Chem Eng. https://doi.org/10.1016/j.jece.2018.01.054

8. Singh J, Dutta T, Kim K-H et al (2018) 'Green' synthesis of metals and their oxide nanoparticles: applications for environmental remediation. J Nanobiotechnology 16:84. https://doi. org/10.1186/s12951-018-0408-4

9. Daniel M-C, Astruc D (2004) Gold nanoparticles: assembly, supramolecular chemistry, quantum-size-related properties, and applications toward biology, catalysis, and nanotechnology. Chem Rev 104:293-346

10. Ravishankar Rai V, Jamuna Bai a. (2011) Nanoparticles and their potential application as antimicrobials. Formatex 197-209

11. Chernousova S, Epple M (2013) Silver as antibacterial agent: ion, nanoparticle, and metal. Angew Chemie Int Ed 52:1636-1653

12. Chaloupka K, Malam Y, Seifalian AM (2010) Nanosilver as a new generation of nanoproduct in biomedical applications. Trends Biotechnol 28:580-588

13. Navaladian S, Viswanathan B, Viswanath RP, Varadarajan TK (2007) Thermal decomposition as route for silver nanoparticles. Nanoscale Res Lett. https://doi.org/10.1007/s11671-006-9028-2

14. Sreeram KJ, Nidhin M, Nair BU (2008) Microwave assisted template synthesis of silver nanoparticles. Bull Mater Sci. https://doi. org/10.1007/s12034-008-0149-3

15. Hajos M, Stypuła B, Starowicz M, Kasprzyk D (2011) Electrochemical synthesis of silver nanoparticles in alcoholic electrolytes. Arch Metall Mater. https://doi.org/10.2478/v10172-011-0016-x

16. Shankar SS, Ahmad A, Sastry M (2003) Geranium leaf assisted biosynthesis of silver nanoparticles. Biotechnol Prog. https:// doi.org/10.1021/bp034070w

17. Verma A, Mehata MS (2016) Controllable synthesis of silver nanoparticles using Neem leaves and their antimicrobial activity. J Radiat Res Appl Sci 9:109-115. https://doi.org/10.1016/j.jrras 2015.11.001

18. Shankar SS, Rai A, Ahmad A, Sastry M (2005) Controlling the optical properties of lemongrass extract synthesized gold nanotriangles and potential application in infrared-absorbing optical coatings. Chem Mater 17:566-572. https://doi.org/10.1021/ $\mathrm{cm} 048292 \mathrm{~g}$

19. Huang J, Li Q, Sun D et al (2007) Biosynthesis of silver and gold nanoparticles by novel sundried Cinnamomum camphora leaf. Nanotechnology. https://doi.org/10.1088/09574484/18/10/105104

20. Ankamwar B, Damle C, Ahmad A, Sastry M (2005) Biosynthesis of gold and silver nanoparticles using Emblica officinalis fruit extract, their phase transfer and transmetallation in an organic solution. J Nanosci Nanotechnol. https://doi.org/10.1166/ jnn.2005.184

21. Rajasekharreddy P, Rani PU, Sreedhar B (2010) Qualitative assessment of silver and gold nanoparticle synthesis in various plants: a photobiological approach. J Nanoparticle Res. https://doi. org/10.1007/s11051-010-9894-5
22. Rostami-Vartooni A, Nasrollahzadeh M, Salavati-Niasari M, Atarod M (2016) Photocatalytic degradation of azo dyes by titanium dioxide supported silver nanoparticles prepared by a green method using Carpobrotus acinaciformis extract. J Alloys Compd. https://doi.org/10.1016/j.jallcom.2016.07.253

23. Nasrollahzadeh $M$, Mohammad Sajadi $S$, Rostami-Vartooni $A$, Khalaj $\mathrm{M}$ (2015) Green synthesis of $\mathrm{Pd} / \mathrm{Fe}_{3} \mathrm{O}_{4}$ nanoparticles using Euphorbia condylocarpa M. bieb root extract and their catalytic applications as magnetically recoverable and stable recyclable catalysts for the phosphine-free Sonogashira and Suzuki coupling reactions. J Mol Catal A: Chem. https://doi.org/10.1016/j. molcata.2014.09.029

24. Nasrollahzadeh M, Sajadi SM, Rostami-Vartooni A, Bagherzadeh M (2015) Green synthesis of Pd/CuO nanoparticles by Theobroma cacao L. seeds extract and their catalytic performance for the reduction of 4-nitrophenol and phosphine-free Heck coupling reaction under aerobic conditions. J Colloid Interface Sci. https://doi.org/10.1016/j.jcis.2015.02.009

25. Nasrollahzadeh M, Mohammad Sajadi S, Rostami-Vartooni A et al (2016) Green synthesis of the Pd nanoparticles supported on reduced graphene oxide using barberry fruit extract and its application as a recyclable and heterogeneous catalyst for the reduction of nitroarenes. J Colloid Interface Sci. https://doi. org/10.1016/j.jcis.2015.12.036

26. Li S, Shen Y, Xie A et al (2007) Green synthesis of silver nanoparticles using Capsicum annuum L. extract. Green Chem 9:852. https ://doi.org/10.1039/b615357g

27. Rostami-Vartooni A, Nasrollahzadeh M, Alizadeh M (2016) Green synthesis of perlite supported silver nanoparticles using Hamamelis virginiana leaf extract and investigation of its catalytic activity for the reduction of 4-nitrophenol and Congo red. J Alloys Compd 680:309-314. https://doi.org/10.1016/j.jallc om.2016.04.008

28. Safari J, Enayati Najafabadi A, Zarnegar Z, Farkhonde Masoule S (2016) Catalytic performance in 4-nitrophenol reduction by $\mathrm{Ag}$ nanoparticles stabilized on biodegradable amphiphilic copolymers. Green Chem Lett Rev 9:20-26

29. Lim SH, Ahn E-Y, Park Y (2016) Green synthesis and catalytic activity of gold nanoparticles synthesized by artemisia capillaris water extract. Nanoscale Res Lett 11:474. https://doi. org/10.1186/s11671-016-1694-0

30. Begum R, Farooqi ZH, Ahmed E et al (2017) Catalytic reduction of 4-nitrophenol using silver nanoparticles-engineered poly $(\mathrm{N}$ isopropylacrylamide-co-acrylamide) hybrid microgels. Appl Organomet Chem. https://doi.org/10.1002/aoc.3563

31. Saha S, Pal A, Kundu S et al (2010) Photochemical green synthesis of calcium-alginate-stabilized ag and au nanoparticles and their catalytic application to 4-nitrophenol reduction. Langmuir. https://doi.org/10.1021/la902950x

32. Sharma M, Mishra A, Kumar V, Basu S (2016) Green synthesis of silver nanoparticles with exceptional colloidal stability and its catalytic activity toward nitrophenol reduction. NANO. https:// doi.org/10.1142/s1793292016500466

Publisher's Note Springer Nature remains neutral with regard to jurisdictional claims in published maps and institutional affiliations. 